\title{
Market Acceptability of Mykovam among Coconut Farmers In San Pablo City, Laguna
}

\author{
Gabriel Mikhail M Gonzales ${ }^{1 *}$ and Bates M Bathan ${ }^{2}$ \\ ${ }^{1}$ B.S. Agricultural Economics Graduate University of the Philippines Los Baños, Philippines
}

${ }^{2}$ Department of Agricultural and Applied Economics, College of Economics and Management, University of the Philippines Los Baños, Philippines

*Corresponding author: Gabriel Mikhail M Gonzales, B.S. Agricultural Economics Graduate, University of the Philippines Los Baños, Philippines

\begin{abstract}
The study analyzed the market acceptability of Mykovam, a biofertilizer developed by UPLB BIOTECH, among coconut farmers in San Pablo City, Laguna. It determined the coconut farmer's level of knowledge of organic and chemical fertilizers and the level of acceptability on Mykovam and its attributes. Using multistage sampling, 83 coconut farmers were randomly selected from 15 barangays. Descriptive analysis and Likert scale rating analysis were used in the study. Results showed that more respondents were moderately and extremely knowledgeable on organic fertilizers than of chemical fertilizers. The seven Mykovam attributes, namely price, materials used, smell, packaging, label, ease of application and amount of application and its overall acceptability were found to be acceptable. The study recommended the improvement of the knowledge dissemination program of DA-PCA and improved promotion of Mykovam by UPLB-BIOTECH.
\end{abstract}

Keywords: Market acceptability; Biofertilizer; Coconut.

\section{Introduction}

Mykovam is a biological fertilizer developed by the University of the Philippines Los Banos - National Institute of Biotechnology and Applied Microbiology (UPLB BIOTECH). It is a mycorrhizal inoculant for agricultural crops, fruit trees and forest trees. The vesicular-arbuscular mycorrhizal fungus in Mykovam helps in the intake of nutrients and absorption of water, inhibits root pathogenic infections, and boosts the tolerance of the plant against extreme dry seasons and heavy metals [1,2]. UPLB BIOTECH in partnership with the Federation of Free Farmers conducted studies on the efficacy of Mykovam on coconut seedlings and these revealed longer height and stem diameter and a greater number of leaves for seedlings applied with Mykovam [3]. Other studies also showed the positive effect of Mykovam on the growth of beauty leaf (Calophyllum inophyllum) [4], Jatropha [5,6], corn [7] and banana [8].

According to Chief Raul Alfiler of the Epidemiology-Entomology Division of the Department of Agriculture-Philippine Coconut Authority (DA-PCA), 13 municipalities in Laguna were infested by coconut scale insect in [9]. A scale insect is a small plant parasite that grows in a colony under a leaf and feeds on plant sap causing the yellowing and wilting of leaves. This prevents photosynthetic activities which leads to premature nut fall and lower yield. To control the outbreak, the following were implemented: cutting of senile and infested trees, a massive spraying of Cochin and pesticide, pruning of leaves of young and moderately affected trees, production and release of biocontrol agents, and application of fertilizers on leaf pruned and sprayed trees. San Pablo City is one of the affected municipalities in Laguna and as they to recover from this infestation, it is imperative that coconut farmers adopt measures that will improve farm productivity. One measure that can be adopted is the use of fertilizer. Various researches of DA-PCA revealed that low yield of coconut trees is attributed to potassium, chlorine, nitrogen and sulfur levels in soil [10]. Ammonium phosphate and complete fertilizers, in addition to salt, are annually distributed by DA-PCA in the area with the goal of increasing coconut productivity. A safer, cost-effective and environment-friendly alternative to chemical fertilizers are biofertilizers [11-13] such as Mykovam [3]. Before this agricultural input can be introduced in the area, it is necessary to analyze its market acceptability among the target users, hence this study. The specific objectives of this study are to determine the coconut farmer's level of knowledge on organic and chemical fertilizers and to assess the level of acceptability on Mykovam and its attributes. 


\section{Research Methodology}

\section{Selection of the study area}

San Pablo City was chosen as the study area being one of the top coconut-producing areas in Laguna. It is an important source of coconut for the province and to its nearby provinces. In terms of location, it is a good target market for Mykovam being relatively accessible to UPLB BIOTECH as compared to other coconutproducing municipalities in the province.

\section{Sampling procedure and data requirements}

Based on the list of coconut farmers provided by the Department of Agriculture - Philippine Coconut Authority (DA-PCA) outpost in Alaminos, Laguna, the population size was 3,000. Multistage sampling technique was employed where 15 out of the 80 barangays in San Pablo City were randomly selected. The 15 barangays were San Isidro, Sto. Niño, Concepcion, San Juan, Sta. Maria, Bautista, Del Remedio, Dolores, San Jose, San Mateo, Sta. Catalina, Sta. Filomena, Sta. Maria Magdalena, Sta. Veronica, and Santiago I. From each barangay, seven respondents were chosen using simple random sampling. Of the total 100 sample respondents, 17 respondents had some response errors, thus a total of 83 sample coconut farmers were used in the study. Using a pre-tested interview schedule, primary data were collected from the coconut farmer respondents. These include their socio-economic and farm-specific characteristics, answers to the questions that measure their level of knowledge on chemical and organic fertilizers, and their level of acceptability on Mykovam and its attributes. Before the level of acceptability was measured, the respondents were presented with Mykovam (Figure 1) and its developers, users, methods of application, and benefits; and shown before-and-after photos of experiments depicting crop responses to Mykovam application.

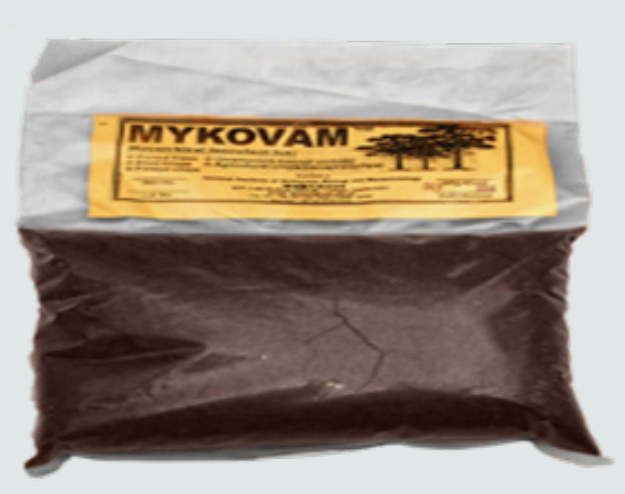

Figure 1: UPLB-Biotech Mykovam

\section{Analytical Tools}

Descriptive analysis was used to describe the primary data collected from the coconut farmer respondents. To measure the level of knowledge on chemical and organic fertilizers, 12 true-orfalse questions were asked from the respondents; in particular, 6 questions for knowledge on chemical fertilizers and 6 questions for knowledge on organic fertilizers. In addition to "true" and "false" answers, "do not know" was also included to eliminate or minimize their chances of guessing. The correct answers to the questions were not all "true" or "false" to prevent the respondents from having a certain response pattern. Respondents who answered six correct answers were classified as extremely knowledgeable, four to five as moderately knowledgeable, one to three as slightly knowledgeable, and zero as not knowledgeable. The level of knowledge was expressed as a percentage and is computed as the number of correct answers over six multiplied by 100 . Likert scale ratings were used to determine the level of acceptability on Mykovam and its attributes. Seven attributes, namely price, materials used, smell, packaging, label, ease of application and amount application were considered in the study. Overall acceptability of the product was also determined. The ratings used are as follows: 1 = very unacceptable, 2 = unacceptable, 3 = neither acceptable nor unacceptable; $4=$ acceptable and $5=$ very acceptable. Since the ratings are ordinal data, modal values were analyzed. The frequency of positive responses (i.e., 4 and 5) was also compared to the frequency of nonpositive responses (i.e., 1, 2 and 3).

\section{Results and Discussion}

\section{Socio-economic characteristics of the coconut farmer respondents}

Table 1: Socio-economics characteristics of the 83 sample coconut farmers, San Pablo City, 2019.

\begin{tabular}{|c|c|c|}
\hline Characteristic & $\begin{array}{l}\text { Number } \\
(n=83)\end{array}$ & Percentage \\
\hline \multicolumn{3}{|l|}{ Sex } \\
\hline Male & 57 & 68.67 \\
\hline Female & 26 & 31.33 \\
\hline \multicolumn{3}{|c|}{ Civil status } \\
\hline Married & 64 & 77.11 \\
\hline Single & 6 & 7.23 \\
\hline Widowed & 13 & 15.66 \\
\hline Mean Age & \multicolumn{2}{|c|}{58} \\
\hline \multicolumn{3}{|c|}{ Educational attainment } \\
\hline Finished tertiary education & 24 & 28.92 \\
\hline Reached tertiary education & 9 & 10.84 \\
\hline Finished secondary education & 12 & 14.46 \\
\hline Reached secondary education & 5 & 6.02 \\
\hline Finished primary education & 25 & 30.12 \\
\hline Reached primary education & 8 & 9.64 \\
\hline Mean Years of Formal Schooling & \multicolumn{2}{|c|}{9} \\
\hline Mean Household Size & \multicolumn{2}{|c|}{5} \\
\hline \multicolumn{3}{|c|}{ Land ownership } \\
\hline Owner & 51 & 61.45 \\
\hline Tenant & 32 & 38.55 \\
\hline $\begin{array}{l}\text { Mean Annual Income from Coconut } \\
\text { Production (PhP) }\end{array}$ & \multicolumn{2}{|c|}{18,592} \\
\hline
\end{tabular}


Majority of the coconut farmer respondents were male, married, finished primary education, and landowners (Table 1). On average, they are old with a mean age of 58 years old with a household size of 5 (Table 1) The respondents also reported a mean annual income from coconut production of $\mathrm{PhP}$ 18,592 (Table 1). This is very far from the annual poverty threshold of PhP 125,772 for a family of five [13]. The sample respondents, therefore, represent the typical coconut farmers in the Philippines which are among the poorest of the poor in terms of poverty incidence.

\section{Level of knowledge of chemical and organic fertilizers}

Table 2: Knowledge questions about chemical and organic fertilizers.

\begin{tabular}{|c|c|c|c|}
\hline Question & $\begin{array}{l}\text { Correct } \\
\text { answer }\end{array}$ & \multicolumn{2}{|c|}{ Respondents who answered correctly } \\
\hline \multicolumn{2}{|l|}{ On chemical fertilizers } & $\begin{array}{l}\text { Frequency } \\
(\mathrm{n}=83)\end{array}$ & Percentage \\
\hline 1. Chemical fertilizers are derived from the remains or by-products of organisms. & False & 38 & 45.78 \\
\hline $\begin{array}{l}\text { 2. The application of chemical fertilizer allows for the nutrients to be available to the plants } \\
\text { immediately. }\end{array}$ & True & 59 & 71.08 \\
\hline 3. Chemical fertilizers normally contain harmful acids. & True & 63 & 75.90 \\
\hline 4. Chemical fertilizers increase the soil's population of beneficial organisms. & False & 24 & 28.92 \\
\hline $\begin{array}{l}\text { 5. Chemical fertilizers tend to leach or filter away from the plants which can require additional } \\
\text { applications. }\end{array}$ & True & 61 & 73.49 \\
\hline $\begin{array}{l}\text { 6. Some examples of chemical fertilizers are ammonium chloride, ammonium nitrate, ammoni- } \\
\text { um phosphate, ammonium sulphate, and urea. }\end{array}$ & True & 70 & 84.34 \\
\hline \multicolumn{4}{|l|}{ On organic fertilizers } \\
\hline 1. Organic fertilizers are developed from synthetic materials. & False & 54 & 60.06 \\
\hline $\begin{array}{l}\text { 2. The application of organic fertilizers allows for the faster release of nutrients to the plants as } \\
\text { compared to the application of chemical fertilizers. }\end{array}$ & False & 19 & 22.89 \\
\hline 3. Organic fertilizers are renewable, biodegradable, sustainable, and environment friendly. & True & 77 & 92.77 \\
\hline $\begin{array}{l}\text { 4. The use of organic fertilizers can lead to a high risk of toxic build-ups of chemicals and salts } \\
\text { that can be deadly to plants. }\end{array}$ & False & 51 & 61.45 \\
\hline $\begin{array}{l}\text { 5. Organic fertilizers help improve the structure of the soil and increase the water holding } \\
\text { capacity of the soil. }\end{array}$ & True & 72 & 86.75 \\
\hline $\begin{array}{l}\text { 6. Some examples of organic fertilizers are compost, manure, and other by-products of organ- } \\
\text { isms. }\end{array}$ & True & 80 & 96.39 \\
\hline
\end{tabular}

Table 3: Knowledge score on chemical fertilizers of 83 sample coconut farmers, San Pablo City, 2019.

\begin{tabular}{|c|c|c|}
\hline Knowledge score & Number & Percentage \\
\hline $0 / 6$ & 1 & 1.2 \\
\hline $1 / 6$ & 4 & 4.82 \\
\hline $2 / 6$ & 5 & 6.02 \\
\hline $3 / 6$ & 20 & 24.1 \\
\hline $4 / 6$ & 30 & 36.14 \\
\hline $5 / 6$ & 17 & 20.48 \\
\hline $6 / 6$ & 6 & 7.23 \\
\hline TOTAL & 83 & 100 \\
\hline MEAN & $3.80 / 6$ & \\
\hline 83 & & \\
\hline
\end{tabular}

The 83 sample coconut farmers were asked knowledge questions about chemical and organic fertilizers. The questions and correct answers are presented below (Table 2). Of all the knowledge questions about chemical and organic fertilizers, it is worth noting that only a few respondents know that chemical fertilizers are not derived from the remains or by-products of organisms and do not increase the soil's population of beneficial organisms and that the application of organic fertilizers does not allow for the faster release of nutrients to the plants as compared to the application of chemical fertilizers. About 36 percent and 24 percent of the respondents have a score of 4 and 3 , respectively. This means that a high percentage of them answered at least half of the questions correctly. Only about 7 percent of the respondents got a perfect score. In addition, the average number of their correct answers was 3.80 or $63.25 \%$ (Table 2). These findings were not expected considering that DA-PCA, prior to their annual distribution of free chemical fertilizers, have their field technicians conduct seminars and meetings with farmers, distribute pamphlets, demonstrate application methods, and give assistance to farmers during actual field application. More than 80 percent of the respondents answered half of the questions correctly while only 8 percent got a perfect score. In addition, the average number of their correct answers was 4.25 or $70.88 \%$. When compared with Table 3 , it can be inferred that the respondents were more knowledgeable of organic fertilizers as can be seen by their higher average score for organic fertilizers than for chemical fertilizers $(70.88 \%>63.25 \%)$. This can be attributed to the fact that organic fertilizers along with their components, application methods, and uses are easier to learn 
and understand as compared to chemical fertilizers (Table 4). On the other hand, the Tobit regression model was not significant at $10 \%$ level of probability, hence no significant determinants of knowledge score on organic fertilizers were identified.

Table 4: Knowledge score on organic fertilizers of 83 sample coconut farmers, San Pablo City, 2019.

\begin{tabular}{|c|c|c|}
\hline Knowledge score & Number & Percentage \\
\hline $0 / 6$ & 0 & 0 \\
\hline $1 / 6$ & 2 & 2.41 \\
\hline $2 / 6$ & 4 & 4.82 \\
\hline $3 / 6$ & 14 & 16.87 \\
\hline $4 / 6$ & 21 & 25.3 \\
\hline $5 / 6$ & 35 & 42.17 \\
\hline $6 / 6$ & 7 & 8.43 \\
\hline TOTAL & 83 & 100 \\
\hline MEAN & \multicolumn{2}{|c|}{$4.25 / 6$} \\
\hline
\end{tabular}

\section{Level of acceptability of mykovam and its attributes}

The respondents rated the price of Mykovam as generally acceptable as most of them gave a rating of acceptable (48.2 percent) and very acceptable (39.8 percent) (Table 5). At present, it is sold by UPLB-BIOTECH at PhP 300 per kg which the respondents find as generally acceptable. For materials used and smell, approximately 86 to 88 percent of the respondents gave a generally acceptable rating (Table 5). For the materials used, most of the respondents liked Mykovam for it is made of pure organic materials, and therefore, does not have any negative effects on the crops and environment. In terms of smell, almost all the respondents said that they liked Mykovam since it does not have foul odor like manure and chemical fertilizers. For packaging, about 63 percent and 23 percent rated it as acceptable and very acceptable, respectively (Table 5). Almost the same results were observed for the product label where 65 percent rated it as acceptable, and 24 percent rated it as very acceptable (Table 5). Also, it must be noted that for the labelling, most of the respondents said that they liked the clear instructions about product usage on the label.

For the attributes related to Mykovam application, namely the ease of application and amount of application, about 91 to 95 percent rated both as generally acceptable (Table 5). Furthermore, almost all the respondents said that the amount of application, which is one teaspoon per tree, was generally acceptable to them since it is only applied once throughout the tree's lifetime. For the ease of application, majority said that the application method of just digging one small hole a meter away from the tree was easy for them to do. Finally, the overall acceptability of Mykovam was rated by most of the respondents as acceptable (61.45 percent) and very acceptable (25.30 percent) (Table 5). Generally, the seven attributes of Mykovam plus its overall acceptability received positive responses ( 4 and 5 ratings) from the respondents with only minimal non-positive responses $(1,2$, and 3 ratings) (Table 5). Moreover, the amount of application and ease of application attributes received the two highest positive responses at 95 percent and 91 percent, respectively (Table 5). Thus, the application method of digging one small hole a meter's length from each tree and the one teaspoon per tree and one-time application of Mykovam were indeed generally acceptable to the respondents (Table 5).

Table 5: Acceptability ratings on product attributes of Mykovam based on 83 sample coconut farmers, San Pablo City, 2019.

\begin{tabular}{|c|c|c|c|c|c|c|c|c|c|c|}
\hline \multirow{3}{*}{ Attribute } & \multicolumn{10}{|c|}{ Acceptability ratings } \\
\hline & \multicolumn{2}{|c|}{1} & \multicolumn{2}{|c|}{2} & \multicolumn{2}{|c|}{3} & \multicolumn{2}{|c|}{4} & \multicolumn{2}{|c|}{5} \\
\hline & No. & $\%$ & No. & $\%$ & No. & $\%$ & No. & $\%$ & No. & $\%$ \\
\hline 1. Price & 3 & 3.61 & 3 & 3.61 & 4 & 4.82 & 40 & 48.2 & 33 & 39.8 \\
\hline 2. Materials used & 1 & 1.2 & 4 & 4.82 & 7 & 8.43 & 36 & 43.4 & 35 & 42.2 \\
\hline 3. Smell & 0 & 0 & 0 & 0 & 10 & 12.1 & 37 & 44.6 & 36 & 43.4 \\
\hline 4. Packaging & 1 & 1.2 & 2 & 2.41 & 9 & 10.8 & 52 & 62.7 & 19 & 22.9 \\
\hline 5. Label & 0 & 0 & 3 & 3.61 & 6 & 7.23 & 54 & 65.1 & 20 & 24.1 \\
\hline 6. Ease of application & 2 & 2.41 & 2 & 2.41 & 3 & 3.61 & 42 & 50.6 & 34 & 41 \\
\hline $\begin{array}{l}\text { 7. Amount of appli- } \\
\text { cation }\end{array}$ & & & 2 & 2.41 & 2 & 2.41 & 45 & 54.2 & 34 & 41 \\
\hline 8. Overall & 0 & 0 & 10 & 12.1 & 1 & 1.2 & 51 & 61.5 & 21 & 25.3 \\
\hline
\end{tabular}

\section{Conclusion and Recommendations}

The study revealed that the coconut farmers in San Pablo City were moderately knowledge about chemical and organic fertilizers and only few farmers knew about chemical fertilizers not being derived from the remains or by-products of organisms and not increasing the soil's population of beneficial organisms as well as the application of organic fertilizers not allowing for the faster release of nutrients to the plants as compared to the application of chemical fertilizers. In terms of Mykovam attributes, the amount and ease of application were the most acceptable while the overall acceptability of Mykovam was generally acceptable to about 87 percent of the respondents. Based on the results of the study, it is recommended that DA-PCA improves their knowledge dissemination program, particularly to increase the level of 
knowledge of coconut farmers on chemical fertilizers. Although DA-PCA provides chemical fertilizers to their farmer beneficiaries, they could also promote the use of Mykovam and even consider the distribution of this biofertilizer to their beneficiaries apart from the regular chemical fertilizers in their input subsidy program. The UPLB-BIOTECH can improve their promotions by including the knowledge questions on fertilizers in their promotional campaigns, especially those which are known to only few farmers, to highlight further the advantages of organic over chemical fertilizers. They can also put emphasis on the amount and ease of application attributes of Mykovam to attract farmers to adopt this technology.

\section{References}

1. Javier PA, Brown MB (2011) Bio-fertilizers and bio-pesticides research and development at PLB.

2. Dela Cruz, RT (2012) Mykovam: Effective Growth Enhancer for Coconut An article published in the Department of Agriculture-Bureau of Agricultural Research (BAR) Chronicle 13(2).

3. Zarate JT (2018) Efficacy of mykovam on coconut and introduction of mykoplus for crop production.

4. Elefan ES (2015) The effects of soil application of biofertilizers on the early growth of Beauty Leaf.
5. Zarate JT, Fernando LM (2007) Enhancing growth of crops with the help of biofertilizers 32(1): 80-81.

6. Gillado AV, Galang MA, Zarate JT (2015) Growth responses of Kamagong (Diospyros blancoi A. DC) bioinoculation and NPK fertilization.

7. Palis MJ (2012) Increasing corn yield at lower cost through biofertilizer inoculation.

8. Abalos EB, Sampaga LO (2013) Effect of Bio-N, Mycovam, Vermicompost and their Combination on the Growth and Yield of Banana. E International Scientific Research Journal (3).

9. Cabotaje NA (2013) 32 Calabarzon towns affected by coconut scale insect infestation. Philippine Information Agency.

10.Aragon CT (2000) Coconut program area research planning and prioritization.

11. Ritika B, Utpal D (2014) Biofertilizer, a way towards organic agriculture: A review. African Journal of Microbiology Research 8(24): 2332-2343.

12. Mohammadi K, Sohrabi Y (2012) Bacterial biofertilizers for sustainable crop production: A review. Journal of Agricultural and Biological Science 7(5): 307-316.

13. Philippine Statistics Authority (2019) Proportion of poor Filipinos registered at 21.0 percent in the First Semester of 2018.
This work is licensed under Creative Commons Attribution 4.0 License

To Submit Your Article Click Here: Submit Article

DOI: $10.32474 /$ CIACR.2019.07.000266

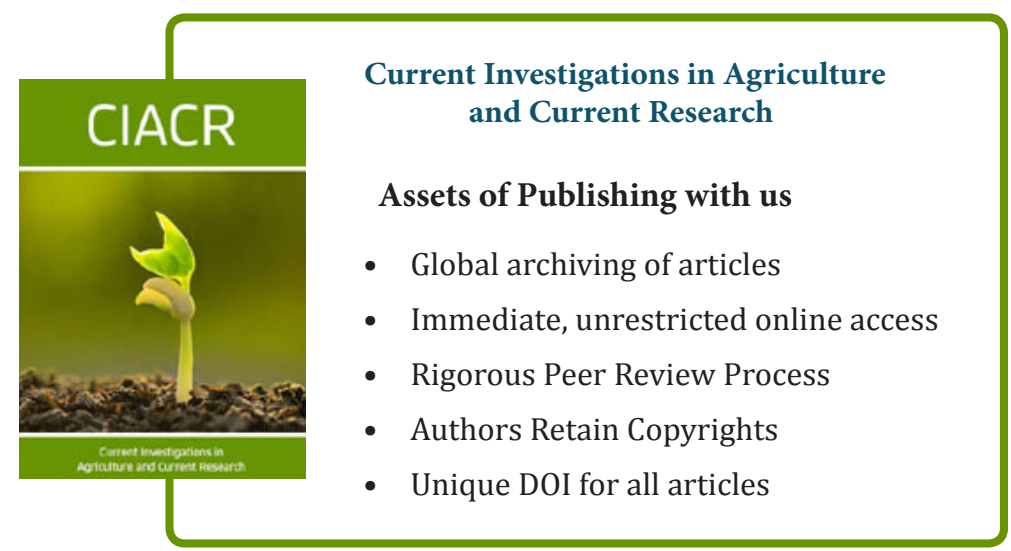

